\title{
Reverting Hegemonic Ideology: Research Librarians and Information Professionals as "Critical Editors" of Wikipedia
}

\section{Paul Thomas}

\begin{abstract}
While many LIS publications have focused on Wikipedia, no LIS study has used intersectional class analysis to consider the site as a transmitter and reproducer of hegemonic ideology. Using both Antonio Gramsci and LIS theorist Michael Harris as starting points, this paper argues that Wikipedia is predicated on a philosophy of pluralism that serves as a transmitter of hegemonic ideology, thereby upholding the oppressive status quo. To counter this issue, the paper encourages librarians to embrace "critical editing" —an approach to Wikipedia editing built around an awareness of power, a penchant for critical literacy, a focus on desocialization, and an emphasis on self-education. The paper concludes with an example of critical editing praxis (dubbed the "Library Repository-to-Wikipedia" method) that research librarians and information professionals can replicate to counteract aspects of Wikipedia that inherently support the status quo and, thus, hegemonic ideology.
\end{abstract}

\section{Introduction}

Wikipedia - the "free encyclopedia anyone can edit" ${ }^{1}$ - has long been a topic of interest to librarians and information professionals; and, during the last decade and a half, library and information science (LIS) journals have published dozens of articles that consider the site's unique approach to article creation/modification, its purported reliability, and its unprecedented size and scope. Another area of research in which LIS scholars have shown an increased interest has been Wikipedia's systemic biases. Most of the publications focusing in this area consider the site's imbalances with regard to gender, sex, sexuality, and politics; however, as of yet, no LIS study has used intersectional class analysis as a framework by which to consider the site's role as a transmitter and reproducer of hegemonic ideology (that is, the dominant and often unconscious worldview that upholds the existing social order, the myriad power structures of that order, and the power of the ruling class).

This paper attempts to fill this hole in the scholarly literature, by taking a Gramscian approach $^{2}$ to the issue. After first reviewing literature about Wikipedia's systemic issues, the article defines what exactly is meant by the terms "hegemony" and "hegemonic ideology." The work then segues into Michael Harris's argument that librarianship has long been predicated

Paul Thomas is a library specialist at the University of Kansas (paulthomas@ku.edu) as well as a student in the Doctor of Philosophy (PhD) degree program in the School of Library and Information Management, Emporia State University. (C2021 Paul Thomas, Attribution-NonCommercial (https://creativecommons.org/licenses/by-nc/4.0/) CC BY NC. 
in the philosophy of pluralism, which claims to be a neutral approach but which really serves as a "handmaiden" 3 of hegemonic ideology, to quote Christine Pawley. After providing evidence that Wikipedia is likewise predicated on this sort of pluralism, the paper details how this philosophical foundation allows Wikipedia to unintentionally serve as a transmitter of oppressive, hegemonic ideology.

The paper's final section encourages users (and librarians in particular) to embrace critical editing, which is an approach to Wikipedia editing influenced by various critical and digital pedagogies. Critical editors recognize that their edits are political (given that they are shaping knowledge), and these editors are always on the lookout for power asymmetries that shape "reliable" sources. The paper then outlines a creative example of critical editing praxis (dubbed the "Library Repository-to-Wikipedia" method) that research librarians and information professionals can use to counteract aspects of Wikipedia that inherently support hegemonic ideology vis-à-vis the existing social order. By embracing critical editing, editors will have the potential to open Wikipedia to many additional types of knowledge, rather than just the "approved" worldview of the dominant class.

\section{Background and Context}

While encyclopedias have been around for hundreds, if not thousands of years, ${ }^{4}$ Wikipedia was the first major encyclopedia to open itself to the public and source all its content from laypersons. What many may not realize is that Wikipedia itself owes its origin to a more traditional encyclopedic project known as Nupedia, which was founded in 1999 by entrepreneur Jimmy Wales and philosophy doctoral student Larry Sanger. ${ }^{5}$ The purpose of Nupedia was to create "the world's largest international, peer-reviewed encyclopedia [that was also] free." ${ }^{\prime \prime}$ To do this, Wales and Sanger sought out world-renowned experts and asked them to write articles about familiar topics. These articles were then peer-reviewed and copyedited before being approved and put online for the whole world to read, free of charge. However, because Nupedia was not a commercial endeavor, Wales and Sanger were unable to pay their editors for their contributions. As such, only a handful of academics participated, resulting in only a few dozen articles ever being written. By 2003, the project effectively collapsed and disappeared in the annals of information organization. ${ }^{7}$

After the implosion of Nupedia, Wales decided to try something new. Inspired by the potential of "wiki" software-that is, "server software that allows users to freely create and edit webpage content using any Web browser" ${ }^{\prime \prime}$-Wales created what he viewed as the spiritual successor to Nupedia, which he called "Wikipedia." Much like Nupedia, Wikipedia was also free and open to the public, but what set it apart from its predecessor is that anyone could contribute to the site-not just those with advanced degrees or professional training. ${ }^{9}$ Understandably, this new project was quite provocative and started an outbreak of moral panic that has refused to die down. Some academics decried this new site as being inherently inaccurate-given that anyone can edit it-and they bemoaned how it would inevitably lead to the downfall of traditional liberal education. ${ }^{10}$ Others - including many research librarians ${ }^{11}$ - realized the possibilities of this new project and actively began to contribute. ${ }^{12}$

Individuals who help build up the site's content (referred to as "editors") can either contribute anonymously or through a registered account (the former method is commonly used by those who want to make quick edits on the fly, whereas the latter method is commonly used by those who want to contribute to the site over a longer period of time). Almost all Wiki- 
pedia articles are open to total modification (some are "locked" to prevent petty vandalism), and an editor need only click the "edit" button at the top of an article to modify its contents. While in theory anything can be added to the site, Wikipedia's "manual of style" stipulates that all content needs to be backed up by "reliable sources" (e.g., citations to books, journal articles, newspapers). ${ }^{13}$

Today, Wikipedia is one of the most-used resources online according to Alexa rankings ${ }^{14}$ and, shockingly, has been cited in everything from court cases ${ }^{15}$ to peer-reviewed articles in rigorously vetted journals like Nature and Science. ${ }^{16}$ As of April 2020, the English version of Wikipedia alone hosts just over 6 million articles, which have collaboratively been created by more than 38.9 million registered users. ${ }^{17}$ (Strictly in terms of articles, Wikipedia dwarfs its de facto rival, the online version of the Encyclopædia Britannica, which hosts only 40,000 articles.) ${ }^{18}$ Today - whether people care to admit it or not-Wikipedia is often the go-to destination for ascertaining a quick bit of information, fact-checking a random piece of trivia, or even beginning the research process. Given that the site is a heavily used sociocultural object that is constantly changing, it is worthy of continuous academic scrutiny.

\section{Wikipedia and Systemic Bias}

The claim that Wikipedia is systemically biased is not a new one, ${ }^{19}$ and numerous studies in the last decade have explored this charge in great detail. While these studies are all subtly different from one another, most (though not all) can be sorted into two broad groups: studies that explore gender, sex, and sexuality bias, or studies that explore sociocultural or political bias.

The largest category of bias studies contains those that consider Wikipedia with regard to gender imbalance. Many of these studies focus on the disproportionately small percentage of Wikipedia editors who identify as women. ${ }^{20}$ An oft-repeated claim in these studies is that around 10 to 20 percent of Wikipedia's editors identify as female-a claim the raw data seem to confirm. Other reports have studied the disproportionately large number of articles written about male subjects, ${ }^{21}$ and still others have analyzed the linguistic and semantic content of the site itself, arguing that, when statistically evaluated, there are clear linguistic correlations between certain phrases/words and their use in articles about persons of specific genders. ${ }^{22}$ Finally, there are a growing number of articles that have criticized the site for lacking proportionate LGBTQ+ articles and editors. ${ }^{23}$

The second category of bias studies are those that explore sociocultural and/or political bias in articles. Several studies have argued that Wikipedia's topical coverage overemphasizes Euro-American culture. ${ }^{24}$ Others have argued that, when it comes to sourcing, the site has a noticeable English-language bias, ${ }^{25}$ and that there are noticeable differences when comparing the content of the English version of Wikipedia to other language variants. ${ }^{26} \mathrm{~A}$ repeated observation, echoed in both scholarly and popular sources, is that Wikipedia and its editors focus heavily on popular culture - sometimes to the detriment of other topics. ${ }^{27}$ Finally, there are a handful of studies that explore whether Wikipedia has a political slant and, if so, what direction the site "leans." 28

This current essay builds from and in many ways unifies this literature by critiquing the site using intersectional class analysis. In particular, this essay considers how Wikipedia serves as a transmitter of the hegemonic ideology that supports the existing "social order," defined here as the laminated "political-economic systems of capitalism and imperialism as well as patriarchy." 29 


\section{Hegemony, Pluralism, and Wikipedia}

The concept of "hegemony" was formulated in the 1930s by Antonio Gramsci, a key neoMarxist thinker and Italian politician. According to Gramsci, the ruling class (that is to say, the bourgeoisie) holds power within the existing social order not only by means of political force and violence, ${ }^{30}$ but also through ideology, which is disseminated via sociocultural structures. ${ }^{31}$ Over time, this slanted ideology gets so widely disseminated that it becomes diffused throughout society, resulting in people seeing this ruling ideology not as a construct but rather as "common sense" - that is, "already existing, self-evident truths" understood as describing the way the world naturally is or should be. ${ }^{32}$ Gramsci argued that this insidious and often imperceptible hegemony was the reason that the bourgeoisie was able to have a stranglehold over the working class (otherwise known as the proletariat) without having to constantly resort to brute force. ${ }^{33}$

Gramsci's formulation of hegemony has been extremely influential in the social sciencesespecially in fields like anthropology, sociology, and political theory-but, unfortunately, as Raber notes, "a search of LIS literature quickly reveals that the work of Antonio Gramsci has had almost no influence on LIS research." ${ }^{34}$ However, a major exception to this blanket statement is Michael Harris, who in 1986 invoked the concept of hegemonic ideology to articulate a theory of - and by extension, the issues with-modern librarianship in the United States. ${ }^{35}$ To fully understand Harris's argument, it is imperative to first start by considering the importance of the "pluralist perspective," which Harris, citing the political theorist William Connolly, defines as a paradigm that:

...portrays the [existing social order] as a balance of power among overlapping ... groupings. Each "group" has some voice in shaping socially binding decisions ... All major groups share a broad system of beliefs and values which encourages conflict to proceed within established channels and allows initial disagreements to dissolve into compromise solutions. ${ }^{36}$

According to Harris, 20th-century librarianship in the United States evolved into a profession that heartily embraced this understanding, eventually leading to the widespread idea that librarians are "apolitical servants of the "people"" who are "completely neutral [when it comes to] social, economic, and political questions." ${ }^{37}$ This underlying philosophy meant that, in time, librarians understood their job as simply collecting what was produced and making it available to all. On the surface, this sort of philosophical turn seems well and good. However, for those committed to true egalitarianism and radical emancipation, it very quickly poses a problem.

Despite the digital revolution, which has enabled the public to produce their own material items, the material found in libraries is largely still produced by "official" (that is, bourgeoisie) entities, like large commercial publishing houses, ${ }^{38}$ production studios, or major record labels. This can clearly be illustrated by walking into almost any public library and pulling a random book off the shelf, or perhaps going to a library-licensed database and clicking on the first journal article that appears; there is a very good chance that the item will not have been self-published by an average individual, but rather mass-produced and distributed by established commercial organizations, including mega publishers like Penguin Random House, HarperCollins, Springer, or Elsevier. ${ }^{39}$ 
Looking at this situation through a Marxian lens, it can be said that these commercial publishers are sustained by the existing power structures in society - in particular, the capitalistic practice of purchasing a product (such as a journal article or a monograph manuscript) and its intellectual rights from authors at low (or no) cost and then selling that product at a much higher price for a profit. ${ }^{40}$ Because this existing system sustains the commercial publishers, ${ }^{41}$ it seems unlikely that they would willingly bite the hand that feeds them by promoting or publishing material that threatens that system in any serious way (for instance, a book called Elsevier's Guide to Using Library Genesis and Sci-Hub).

Furthermore, because many commercial publishers are so large, when taken together they effectively form a market monopoly that very literally controls what is or is not distributed to the world at large. ${ }^{42}$ Authors thus have to publish with them. (To use a simple anecdotal example from academia: many scholars are warned that they have to work with a well-known publisher or else their research will never be read and they will likely fail in an attempt to secure tenure. $)^{43}$ All of this results in material distributed by the commercial publishers broadcasting, either explicitly or implicitly, a desire to preserve the existing social order. This ideology is then internalized by those scholars and researchers who consume that material until it is accepted by most as the common-sensical "way things are." This is hegemonic ideology at work.

All of this has a direct impact on libraries. This is because librarians espouse pluralist ideas like neutrality, meaning that they strive to "provide 'balanced' collections reflecting the wide diversity of views found in pluralistic society." 44 Again, this seems fine until one realizes that the "balanced" and "diverse" material that librarians curate is overwhelmingly produced by the aforementioned publishers, whose material in and of itself promotes the hegemonic ideology that keeps them in power. This means it is impossible for most librarians to truly be apolitical or neutral agents, given that the pluralist ideology they embrace leads to their reproducing (and thereby endorsing) hegemonic ideology - a decidedly political act. ${ }^{45}$ It is for this exact reason that the critical pedagogue Henry Giroux has emphatically argued that "neutrality [is] the basis for a kind of fascist politics." 46

\section{The Pluralist Roots of Wikipedia and the Problem at Hand}

At this point, a reader might be curious how the pluralist perspective, which so far has been discussed in regard to librarianship, is related to Wikipedia. The simple answer is that the pluralist perspective, in many ways, directly informs Wikipedia's policies. To arrive at this conclusion, it is first necessary to take a look at Wikipedia's epistemological grounding. While Wikipedia owes its existence to the functionalist encyclopedia tradition that believes the world can be objectively identified and documented, in many ways the site is a radical humanist project that - at least on the surface-knows no limit, as editors are free to write about pretty much whatever they want. Of course, this freedom has led to the charge that Wikipedia is nothing more than "post-postmodern ...drivel." 47 To overcome this issue, Wikipedia editors have rallied around the driving ethos that the site is epistemologically citational, cataloging only what other reliable sources have documented and commented upon. ${ }^{48}$

The importance of reliability is stressed in a Wikipedia essay appropriately titled "Wikipedia:Reliable sources." This page mandates: "Wikipedia articles should be based on reliable, published sources, making sure that all majority and significant minority views that have appeared in those sources are covered...If no reliable sources can be found on a topic, Wikipedia should not have an article on it" [emphasis added]. ${ }^{49}$ This means that Wikipedia - at least accord- 
ing to its own rhetoric - does not contain what it calls "original research"; it instead aggregates what experts have already published. ${ }^{50}$ Consequently, when a debate about topical coverage comes up, Wikipedia editors often wash their hands of any problem by claiming that the site is a third-party committed to simple, neutral documentation. ${ }^{51}$

Indeed, the idea of "neutrality" is so important to Wikipedia editors that it too is considered a core content policy point that governs the site. Consider the following, taken from the Wikipedia essay entitled "Wikipedia:Neutral point of view":

All encyclopedic content on Wikipedia must be written from a neutral point of view (NPOV), which means representing fairly, proportionately, and, as far as possible, without editorial bias, all of the significant views that have been published by reliable sources on a topic.... Wikipedia aims to describe disputes, but not engage in them. Editors, while naturally having their own points of view, should strive in good faith to provide complete information, and not to promote one particular point of view over another. As such, the neutral point of view does not mean exclusion of certain points of view, but including all verifiable points of view which have sufficient due weight. ${ }^{52}$ [emphasis added]

By embracing both "reliability" and "neutrality," Wikipedia's citational epistemology thus bars the addition of various types of knowledge, including personal opinion, unpublished research, or unverified "corrections" to extant literature - all of which is considered "original research." Instead, the site defers only to the thoughts of "experts," which are found in professionally published sources like journal articles, books, newspaper articles, and professional reports. ${ }^{53}$

It is almost certainly no coincidence that Wikipedia's fixation on "reliable" sources and "neutrality" mirrors the pluralist belief that "collections can be built in a uniform and neutral manner by simply attending to the clearly demarcated body of ...works endorsed by the creators and producers of high culture." ${ }^{54}$ Indeed, Wikipedia, just like the modern library, is very much a pluralistic project; therein lies the problem. As was discussed earlier, pluralism in regard to librarianship can often result in the reproduction of hegemonic ideology by upholding the existing social order. ${ }^{55}$ This means that Wikipedia-being predicated on a strictly citational sort of pluralism that favors only the "neutral" material created by those currently in a state of power - is a site that necessarily reproduces hegemonic ideology as well.

For an example of how this pluralism can cause issues on Wikipedia, consider the myriad sociocultural groups that do not have robust written records, or those cultures that lack a comprehensive writing system all together. Because "neutral" and "reliable" sources (defined by Wikipedia editors as monographs, journal articles, and the like) have not been published about these groups, much of their collective knowledge-their myths, legends, histories, beliefs, languages, politics - cannot be systematically added to Wikipedia, since doing so would constitute "original research." ${ }^{56}$ Or consider, perhaps, the many women, people of color, and/ or people of lower socioeconomic class who have almost certainly shaped history but whom the "reliable" history books have omitted. They too must be omitted from Wikipedia.

Wikipedia's pluralist citation policy thus does two main things: First, it violently erases those groups not mentioned in "reliable sources" while simultaneously overemphasizing the role of the privileged groups (who are disproportionately white, male Euro-Americans) 
that are mentioned in these sources, thereby reaffirming and reproducing the (white, male Euro-American) hegemony of the status quo. Second, it reasserts the "common sense" idea that the only reliable sources are those made by (often large) commercial publishers. This, in turn, leads to the continuing hegemony of the modern publishing industry and its performative ability to construct the "truth" about the very world we live in. The proverbial cherry on top is that Wikipedia's opposition to non-neutral editing squashes many ways for people to critique this pluralism, and thus ideological hegemony itself.

This situation is made all the more serious by the fact that Wikipedia is what can be called a "digital infrastructure," meaning that it is often uncritically used by many humans connected to the internet, millions of whom use the site as a quick way to check a fact or look up a bit of trivia. Many people uncritically take the content at face value, ${ }^{57}$ regardless of whether there is a reliable, verifiable citation backing up that content. ${ }^{58}$ This means that when hegemonic ideology finds its way into the text of Wikipedia, it is almost always caught up in the nonstop and nigh-subliminal dissemination of information. ${ }^{59}$ Having been quietly dispersed the world over, this hegemonic ideology is unconsciously absorbed by readers, who will then use that information in some real way, thus reaffirming and further diffusing said ideology. From there, it can only snowball.

\section{What Is Already Being Done?}

In response to the systemic biases discussed earlier in this paper, a sizable contingent of Wikipedia editors has initiated projects to right wrongs. ${ }^{60}$ A good illustration of this "Wikiactivism" is the "Women in Red" WikiProject. On Wikipedia, hyperlinks to articles that have not yet been created will appear in bright red, as opposed to the normal blue; this red link functions as a veritable construction sign, letting readers know that editors have not gotten around to working on that specific topic. Because a disproportionate number of articles on the site are about men, the "Women in Red" WikiProject thus strives to actively create articles about women so as "to turn 'redlinks' into blue ones." 61 This targeted editing, it is believed, will help reduce the aforementioned gender bias on Wikipedia. In that regard, the project has been somewhat successful: When it was launched in October 2014, only about 16 percent of the encyclopedia's biographical articles were about women; by October 2019, that number had grown to 18 percent. $^{62}$

Projects like "Women in Red" are laudable efforts (and I proudly consider myself a member of the aforementioned project); but, before Wikipedia celebrants ${ }^{63}$ get too excited, it is important to remember that these projects have their own issues that often go unnoticed. For the purposes of this article, the biggest issue worth noting is that those projects seeking to undo systemic bias almost universally gloss over the fundamentally problematic issue of class and social order. Instead, they are forced to counter bias while still reproducing the existing power structures that have given rise to and/or exacerbated many aspects of oppression. For instance, if an editor wants to undo systemic bias that has excluded the contributions of women of color, that editor will still be forced to edit in a way that is "neutral" and that makes use of "reliable sources" published by bourgeoisie companies - requirements that, as has been noted in this paper, by their very nature preserve the existing social order. ${ }^{64}$

This means that most anti-bias projects function like bandages that cover only surface issues while still leaving articles firmly "enmeshed in discourses of hierarchy, knowledge legitimation, and power." 65 And while it is important to re-emphasize that these anti-bias 
projects are worthwhile and should be supported, even after extensive overhauling, most articles still remain tools of domination, broadcasting hegemonic ideology that promotes the preservation of the existing social order. Consequently, if we want to really improve the situation and weed out hegemonic ideology, our entire approach to "proper" Wikipedia editing and sourcing will need to change. What we need is an intersectional approach that will allow us to root out sexism, racism, classism, and imperialism at the same time.

\section{"Critical Editing": Empowering Wikipedia Editors to Combat Hegemonic Ideology}

The question of how one can "revert" (to use Wiki-speak) hegemonic ideology embedded in the core of the encyclopedia is not an easy one to answer, and it is unlikely that any one method can serve as a permanent panacea. That said, in this present section, I would like to discuss a new philosophy for Wikipedia users that I have formulated called critical editing. ${ }^{66}$ When embraced consistently and committedly by editors, this philosophy has the potential to free the encyclopedia from some of hegemonic ideology's shackles. Furthermore, given the rise of critical librarianship within the last few years, I believe most research librarians and information professionals are in a prime position to serve as critical editors, given their key role in the preservation, transmission, and dissemination of information.

Critical editing is inspired directly by the critical pedagogy of Paulo Freire, ${ }^{67}$ Ira Shor $^{68}$ and Henry Giroux; ${ }^{69}$ the digital pedagogy of Sean Michael Morris, Jesse Stommel, ${ }^{70}$ Matthew A. Vetter, and Keon Pettiway; ${ }^{71}$ and - perhaps most importantly - the fundamental philosophy underpinning critical librarianship. ${ }^{72}$ It can be glossed as a holistic approach to Wikipedia that recognizes the site not as the neutral "sum of all human knowledge," but as a political site of ever-changing knowledge production and reproduction. Critical editors are thus aware that "neutral" editing is an impossible requirement and that calls for neutrality are really calls for the preservation of the oppressive social order. ${ }^{73}$ Critical editors also accept as axiomatic that there are power asymmetries inherent to supposedly "reliable" sources as well as the encyclopedic project as a whole, and that the only way to dismantle these asymmetries is by rigorously scrutinizing articles for unconscious slant, systematically interrogating existing citational practices, and calling attention to what Vetter and Pettiway refer to as "diverse knowledge-making practices" (such as oral tradition) that are often overlooked or marginalized. ${ }^{74}$

Critical editing thus goes far beyond the goals of many Wikipedia-focused anti-bias initiatives (like edit-a-thons) ) $^{75}$ that almost always focus on occasional, localized modifications while ignoring the intersectional issues of the existing social order. Instead, critical editing promotes the constant identification and critiquing of oppressive systems that might allow Wikipedia articles to unconsciously diffuse hegemonic ideology. By directly eschewing the reproduction of hegemonic ideology's oppressive "single voice,"76 critical editing thus actively encourages the sort of emancipatory collaboration that Wikipedia and its supporters have long lauded.

\section{The Four Key Features of Critical Editing}

Implicit in the critical editing approach are four key features, derived from Shor's understanding of critical consciousness: ${ }^{77}$

\section{Criterion 1: Power awareness.}

First, and perhaps most important, critical editors focus on the question of power. Information should never be added thoughtlessly to the site. Instead, a critical editor interrogates where in- 
formation is coming from and questions why the producers of that information were motivated to produce it in the first place. By making an effort to be consciously aware of the questions of power, critical editors can learn to more readily detect the oppressive and often obscure power dynamics that frame and support "impartial" or "reliable" sources. By scrutinizing the power dynamics inherent in their sources and the project itself, editors can learn to ask who benefits from the information they find. On that note, this questioning of power should also be reflexive, forcing the critical editor to recognize that they too are in a position of power, given that they are the ones choosing what content will be added to or removed from Wikipedia.

\section{Criterion 2: Critical literacy.}

Second, critical editors are "critically literate," meaning that they eschew shallow understandings of sources and articles alike, instead coming to know the many different dimensions of any text in question. Often, critical literacy requires the recontextualization of sources; as such, critical editors should recognize that "information resources reflect their creators' expertise and credibility" - as well as biases - and must therefore be "evaluated based on the information need and the context in which the information will be used." ${ }^{78}$ Critical literacy on Wikipedia could include anything from researching a particular source to better understand the intentions of the author, to overhauling articles that have incorrectly included or omitted key sources.

\section{Criterion 3: Desocialization.}

Third, critical editors strive to desocialize themselves and others by "recognizing and challenging" the problematic "myths, values, behaviors, and language learned in mass culture."79 A major aspect of desocialization is metacognitive, meaning that editors should meditate on the ways they often unconsciously think and act that may uphold oppressive systems. While difficult and at times taxing, questioning preconceived notions is imperative if editors want to unlearn harmful patterns of (for instance, sexist, racist, classist, nationalistic) thinking and behaving that for many are deeply internalized. Examples of desocialization on Wikipedia might include actively questioning the provenance of "common sense" claims that reproduce the oppressive social order (such as the doxa that all editing be neutral and unoriginal), or dialoging about potentially problematic editing practices with other editors on "talk pages" (which are special Wikipedia articles designed specifically for editor communication).

\section{Criterion 4: Self-organization and self-education.}

Finally, for the critical editor, the act of contributing to Wikipedia is divorced from "authoritarian relations," 80 meaning that the act has "autonomy from authority-dependence." ${ }^{11}$ Put another way, critical editors should be inspired to contribute content not because they have to (such as students who have been given a mandatory school assignment to "improve an article" or "make a major edit"), but because they want to. This facet is of utmost importance because it is only by breaking from the existing power structures of traditional education and embracing self-direction that the critical editor can strive for anything that resembles liberation.

\section{Praxis Makes Perfect: The "Library Repository-to-Wikipedia" Method of Critical Editing}

As Marilyn Frankenstein argues, "Reflection that is not ultimately accompanied by action to transform the world is meaningless ... rhetoric." ${ }^{82}$ In an effort to avoid meaningless rhetoric, 
this article will now detail a particular method of critical editing praxis that I call the "Library Repository-to-Wikipedia" method.

As has been emphasized several times, the fundamental problem discussed in this article has been Wikipedia's pluralistic ethos, best expressed in its citation policies. This means that issues of hegemonic ideology cannot be ameliorated - and may in fact be exacerbated-simply by the addition of "neutral" and "reliable" sources, since these sources often cause the structural issues in the first place. The only way to effectively combat the "print-centric epistemology [sustaining] existing hegemonies" is by subverting in some way that very epistemology. ${ }^{83}$ This means that a truly emancipatory praxis will need to result in 1) original content that can 2) be added to Wikipedia, while 3) satisfying Wikipedia's "reliability" mandate and 4) challenging hegemonic ideology vis-à-vis the existing social order.

On the surface, this may seem like an impossible task. How can "original research" make its way onto Wikipedia without somehow violating rules about neutrality or reliability? Likewise, what publisher would subvert its own commercial imperative by allowing the wholesale duplication of its content onto a freely accessible resource? My answer to this question is what I have dubbed the "library repository-to-Wikipedia" method, which calls for critical editors to first publish robust encyclopedic articles-replete with a summation of the extant literature, alongside original commentary, discussions of power dynamics, and critiques of the status quo-under a creative commons license via a research library's digital repository. ${ }^{84}$ Being freely licensed, this text can then be integrated into a Wikipedia article, and because this text was released by a reputable publisher (in other words, the research library), the library copy of the article can serve as a reliable source for any instances of original research. An outline of this method is as follows, which in turn is visualized in figure 1:

Step 1: Detect an Issue on Wikipedia: The first step is for the critical editor to detect an issue in Wikipedia's coverage that cannot be overcome simply by standard editing practices. Perhaps the issue in question is the result of systemic asymmetries in the way the site operates (such as the exclusion of indigenous knowledge that might exist only as oral tradition) ${ }_{r}^{85}$ or perhaps it is an instance of "neutral," "reliable" bourgeoisie sources being used to validate "common sense" claims that reproduce hegemonic ideology vis-à-vis the social order.

Step 2: Research and Write Article Offline: Once an issue has been identified, the critical editor begins to construct an article offline that addresses the issue. This work should be modeled on the structure of a Wikipedia article and closely follow the site's manual of style, as this will make eventual Wikipedia integration easier. ${ }^{86}$ When working on this article, a critical editor is encouraged to use copious sources and citations, which they should include alongside their own original, critical research to actively rebut hegemonic ideology.

Step 3: Begin Collaborative Peer Review: Once a critical editor has finished researching and writing their article, they are encouraged to solicit comments about that article from their colleagues or individuals who are otherwise knowledgeable in the area being written about; this is effectively a variant of what Morris and Stommel call "collaborative peer review," wherein authors, referees, and editors openly cooperate on the production of scholarship. ${ }^{87}$ For transparency, the identities of the reviewers can be noted in the article, and a copy of their comments can even be amended to the article as an appendix or a supplemental file.

Step 4: Publish Article via Library Repository: Once a critical editor is satisfied with their article, it is published by a research library via a digital repository. Importantly, the work is released under the Creative Commons Attribution 4.0 International License, which allows for 
the content to be shared, adapted, remixed, or integrated into any project-even commercial ones - as long as the persons adapting the content provide attribution that indexes the original (in other words, a citation); this is a crucial step in allowing full integration into Wikipedia.

Step 5: Integrate Article into Wikipedia: Once the article is in the repository, the critical editor can (thanks to the aforementioned Creative Commons license) copy the contents of their article onto Wikipedia, using it to supplement an existing article on the site or to form the basis for a new Wikipedia article. For instances of original research, the critical editor can simply provide a footnoted citation to the stable version of the article hosted in the library's repository; because the original version of the article was peer-reviewed and published by a reputable organization, it technically satisfies Wikipedia requirements about reliable sourcing.

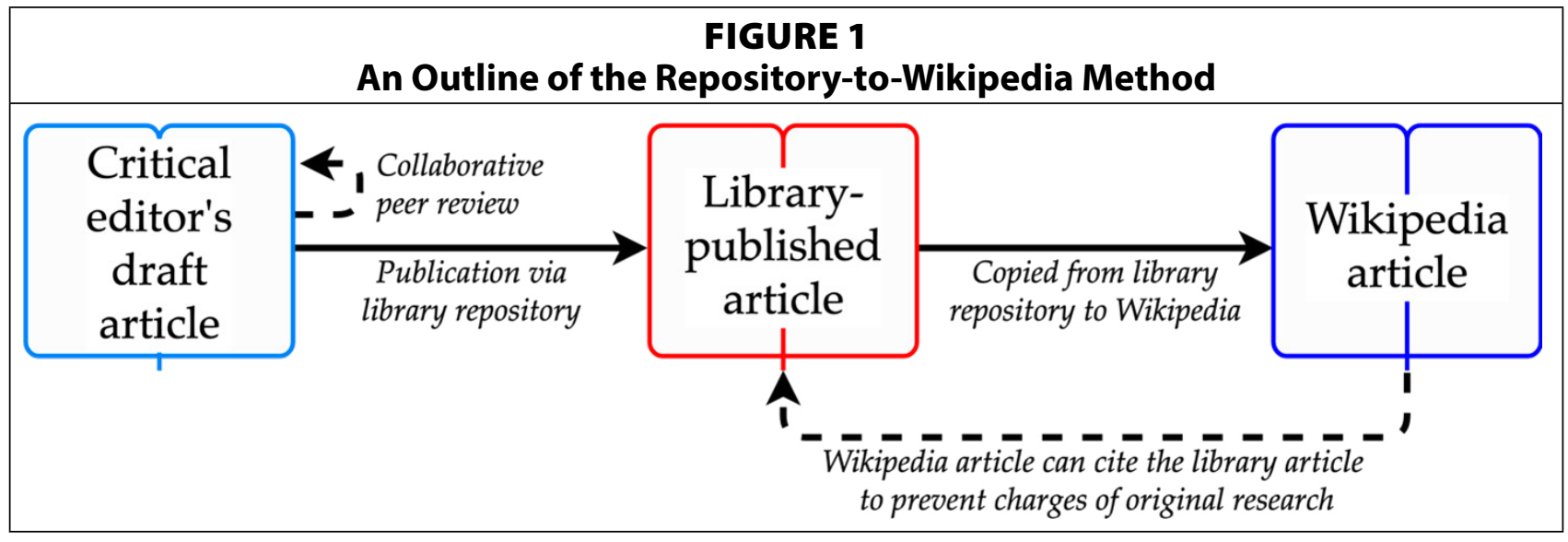

While the practice being described here is new and thus experimental, its fundamentals are based solidly on what one might call "Wiki-precedent" - namely, the fact that many articles on Wikipedia already use text from freely available resources like the 11th edition of Encyclopxdia Britannica (1911), The Jewish Encyclopedia (1901), and the Catholic Encyclopedia (1907-12). ${ }^{88}$ The articles from these reference works lack explicit inline citations, and almost all of them contain what Wikipedia would call "original research," be it critical commentary, a synthesis of multiple sources, judgment calls, or textual extrapolations. However, because these works were published, they have nevertheless been deemed reliable, and many of their otherwise original assertions are backed up on Wikipedia with a citation to the original encyclopedia entry. ${ }^{89}$ This is, in essence, the same method I am promoting here, with the main difference being that library-published sources are more up-to-date and have been written with the express intention of being interpolated into Wikipedia.

At this point a reader might ask why I am championing library repository publishing, rather than encouraging authors to directly publish their articles in open access journals. The fact of the matter is that open access journals are, in many ways, useful tools for breaking the hegemony of the commercial publishing industry. That said, I do believe that, for the purposes of constructing critical encyclopedic texts, library repository publishing arguably allows for greater creative control on the part of the critical editor(s), as said editors do not have to worry so much about scholarly "fit," keeping their entry within 3,000-8,000 words, or adhering to whatever style guide is mandated by a specific journal. Additionally, library repository publishing answers to Jesse Stommel's call for scholars to "broaden the [academic] landscape to make way for dynamic collaboration, new media, and participatory culture" 190 - something 
that many traditional journals have shown a great reluctance to do.

All things considered, the library repository-to-Wikipedia method aligns closely with the spirit of critical editing, given that contributors who embrace the model can:

- Discuss the power structures that have created the knowledge being written about, as well as the power that the author has in organizing said knowledge (criterion 1);

- Criticize, synthesize, or supplement existing sources without being accused of "original research" (criterion 2);

- Break from aspects of the hegemonic publishing industry while still producing widely disseminated research, thereby refusing to uphold an oppressive system (criterion 3); and

- Openly collaborate with others to create a well-written, multidimensional article of scholarship, which can be edited even after it has been officially published, thereby encouraging voluntary upkeep on the part of the contributor(s) (criterion 4).

Once again, however, the celebrants should restrain any uncritical optimism. The library repository-to-Wikipedia method is not a perfect solution and has its drawbacks, with perhaps the most notable being that, while it subverts a major aspect of the hegemonic publication system, it still relies on (and thus reproduces) key aspects of the status quo, such as peer review or a reliance on an institution's imprimatur to grant a sense of reliability. Additionally, some traditionalist Wikipedia editors may view this approach as a way to "cheat" the system, but I would counter that this method of praxis, when done transparently and in good faith, is nothing more than a creative way to leverage the site's exact rules for the betterment of society.

Of course, no solution is ever a perfect cure-all, but research librarians and other information scholars should not ignore the truly transformative potential that the "library repositoryto-Wikipedia" method has to offer.

\section{Conclusion}

As a resource providing millions of free articles to billions of people the world over, Wikipedia is a revolutionary platform that has the potential to trigger a massive paradigm shift in fields like library studies and information science. With that said, the site's oft-ignored predication on the pluralist philosophy means that Wikipedia-like the modern institution that is librarianship -is complicit in the reproduction of ruling class ideology and has thus become what Pawley once called "hegemony's handmaiden." ${ }^{91}$ In direct response to this issue, the present paper outlines the critical editing approach (an intentional and non-neutral approach built around the awareness of power, a penchant for critical literacy, a focus on desocialization, and an emphasis on self-education), which I have articulated as a way to break the grip of hegemonic ideology; likewise, I intend for the library repository-to-Wikipedia method of praxis to serve as a critical model that can be replicated and perfected by LIS professionals of varying experience levels who otherwise are united by a wish to see Wikipedia achieve its emancipatory potential.

At this point, I anticipate that the reader may be left with one major question (and one that I have purposely held off answering until now): Why librarians? Why should the LIS field become what is effectively the Wiki-vanguard, responsible for marching through the institutions and spreading the word about critical editing? The answer is simple and has been referenced several times in this article: librarians for decades have played a part in maintaining hegemonic ideology with the pluralistic way they curate knowledge. ${ }^{92}$ Given this unfortunate history, it only makes sense for the librarians and information professionals - many of 
whom are now openly dedicated to democratic and egalitarian projects like Wikipedia - to be the ones on the digital frontlines, fighting against the reproduction of power structures by becoming critical editors.

\section{Acknowledgments}

The author would like to thank Dr. Michael Widdersheim, Carmen Orth-Alfie, Karna Younger, Tami Albin, Josh Bolick, Marianne Reed, Natalie Mahan, Brian Moss, Wendi Arant Kaspar, and the anonymous $C \mathcal{E} R L$ peer-reviewers for their thoughtful insights, criticisms, and suggestions. Your contributions have made this a much stronger work of scholarship.

\section{Notes}

1. "Main Page," Wikimedia Foundation, last modified April 18, 2020, https://en.wikipedia.org/w/index. php?title=Main_Page\&oldid=951809097.

2. The Gramscian approach allows for a Marxian critique that is also intersectional, given that it "does not privilege economic factors over race, gender, and sexual identity factors." Richard R. Valencia, Chicano School Failure and Success: Past, Present, and Future (London, UK: Routledge, 2011), 177.

3. Christine Pawley, "Hegemony's Handmaid? The Library and Information Studies Curriculum from a Class Perspective," Library Quarterly 68, no. 2 (1998): 123-44.

4. Dan O'Sullivan, "What Is an Encyclopedia? From Pliny to Wikipedia," in Critical Point of View: A Wikipedia Reader, eds. Geert Lovink and Nathaniel Tkacz, Ink Reader (Amsterdam, Netherlands: Institute of Network Cultures, 2011), 34-49, https://www.networkcultures.org/_uploads/\%237reader_Wikipedia.pdf.

5. Andrew Lih, The Wikipedia Revolution: How a Bunch of Nobodies Created the World's Greatest Encyclopedia (New York, NY: Hyperion, 2009), 32; Dan O'Sullivan, Wikipedia: A New Community of Practice? (Farnham, UK: Ashgate, 2009), 121.

6. Jimmy Wales and Larry Sanger, "Welcome to Nupedia.com," archived at http://web.archive.org/ web/20010118225800/http://www.nupedia.com/.

7. O'Sullivan, Wikipedia, 121; Lih, The Wikipedia Revolution, 43-45; Joseph Michael Reagle, Good Faith Collaboration: The Culture of Wikipedia, eds. Michael Buckland and Jonathan Furner, History and Foundations of Information Science (Cambridge, MA: The MIT Press, 2010), 6.

8. B. Leur and W. Cunningham, "What Is Wiki?" www.wiki.org/wiki.cgi?WhatIsWiki.

9. Paul Thomas, "Wikipedia," in Be Credible: Information Literacy for Journalism, Public Relations, Advertising and Marketing Students, eds. Peter Bobkowski and Karna Younger (Lawrence, KS: William Allen White School of Journalism and Mass Communications, 2018), https://doi.org/10.17161/1808.27350; Lih, The Wikipedia Revolution, 43-45; O'Sullivan, Wikipedia, 121; Reagle, Good Faith Collaboration, 6.

10. For a robust and comprehensive review of Wikipedia critiques, see: "Criticism of Wikipedia," Wikimedia Foundation, last modified May 3, 2020, https://en.wikipedia.org/w/index.php?title=Criticism_of_ Wikipedia\&oldid $=954695465$.

11. See, for instance: Leveraging Wikipedia: Connecting Communities of Knowledge, ed. Merrilee Proffitt (Chicago, IL: ALA Editions, 2018).

12. For more on this divide, see: Thomas Leitch, Wikipedia U: Knowledge, Authority, and Liberal Education in the Digital Age (Baltimore, MD: Johns Hopkins University Press, 2014).

13. John Broughton, Wikipedia: The Missing Manual (Sebastopol, CA: O’Reilly Media, Inc., 2008); Thomas, "Wikipedia."

14. Alexa, "Wikipedia.Org Traffic Statistics," Alexa Internet, Inc., https://www.alexa.com/siteinfo/wikipedia. org.

15. Jason Miller and Hannah Murray, "Wikipedia in Court: When and How Citing Wikipedia and Other Consensus Websites Is Appropriate," St. John's Law Review 84, no. 2 (2010): 633-56, https://scholarship.law.stjohns. edu/lawreview/vol84/iss2/2.

16. M. Dylan Bould et al., "References That Anyone Can Edit: Review of Wikipedia Citations in Peer Reviewed Health Science Literature," BMJ 348 (2014): 1-10, https://doi.org/10.1136/bmj.g1585.

17. “Wikipedia: Size of Wikipedia," Wikimedia Foundation, last modified April 29, 2020, https://en.wikipedia. org/w/index.php?title=Wikipedia:Size_of_Wikipedia\&oldid=95388869.

18. "Wikipedia: Size Comparisons," Wikimedia Foundation, last modified May 2, 2020, https://en.wikipedia. 
org/w/index.php?title=Wikipedia:Size_comparisons\&oldid=954502420.

19. Christoph Hube, "Bias in Wikipedia" (paper presented at the Proceedings of the 26th International Conference on World Wide Web Companion, Perth, Australia, 2017), 717-21, https://doi.org/10.1145/3041021.3053375; Henriette Roued-Cunliffe, "Forgotten History on Wikipedia," in Participatory Heritage, eds. H. Roued-Cunliffe and A. Copeland (London, UK: Facet Publishing, 2017), 67-76.

20. Kelly Doyle, "Minding the Gaps: Engaging Academic Libraries to Address Content and User Imbalances on Wikipedia," in Leveraging Wikipedia: Connecting Communities of Knowledge, ed. Merrilee Proffitt (Chicago, IL: ALA Editions, 2018), 55-69; Marit Hinnosaar, "Gender Inequality in New Media: Evidence from Wikipedia," Journal of Economic Behavior \& Organization 163 (2019): 262-76, https://doi.org/10.1016/j.jebo.2019.04.020; Benjamin Mako Hill and Aaron Shaw, "The Wikipedia Gender Gap Revisited: Characterizing Survey Response Bias with Propensity Score Estimation," PloS one 8, no. 6 (2013), https://doi.org/10.1371/journal.pone.0065782; Eduardo Graells-Garrido, Mounia Lalmas, and Filippo Menczer, "First Women, Second Sex: Gender Bias in Wikipedia" (paper presented at the Proceedings of the 26th ACM Conference on Hypertext \& Social Media, Guzelyurt, Northern Cyprus, 2015), 165-74, https://dl.acm.org/citation.cfm?id=2791036; Paolo Massa and Asta Zelenkauskaite, "Gender Gap in Wikipedia Editing: A Cross Language Comparison," in Global Wikipedia: International and Cross-Cultural Issues in Online Collaboration, eds. Pnina Fichman and Noriko Hara (Lanham, MD: Rowman \& Littlefield, 2014), 85-96; Shyong Tony Lam et al., “WP:Clubhouse? An Exploration of Wikipedia's Gender Imbalance” (paper presented at the Proceedings of the 7th International Symposium on Wikis and Open Collaboration, New York, NY, 2011), 1-10, https://dl.acm.org/citation.cfm?id=2038560.

21. Graells-Garrido, Lalmas, and Menczer, "First Women, Second Sex," 165-74; Joseph Michael Reagle and Lauren Rhue, "Gender Bias in Wikipedia and Britannica," International Journal of Communication 5 (2011): 1138-58, https://pdfs.semanticscholar.org/58ed/d95b593fe5237e0f0bda2f4d09f94b3f3353.pdf.

22. Graells-Garrido, Lalmas, and Menczer, "First Women, Second Sex," 165-74; Hube, "Bias in Wikipedia," 717-21; Claudia Wagner et al., "It's a Man's Wikipedia? Assessing Gender Inequality in an Online Encyclopedia" (paper presented at the Ninth International AAAI Conference on Web and Social Media, Oxford, UK, 2015), https://arxiv.org/abs/1501.06307; Claudia Wagner et al., "Women through the Glass Ceiling: Gender Asymmetries in Wikipedia," EPJ Data Science 5, no. 5 (2016): 1-24, https://doi.org/10.1140/epjds/s13688-016-0066-4; Ruediger Glott, Philipp Schmidt, and Rishab Ghosh, "Wikipedia Survey: Overview of Results," United Nations University: Collaborative Creativity Group (2010): 1158-78, www.wikipediasurvey.org/docs/Wikipedia_Overview_15March2010FINAL.pdf.

23. Rachel Wexelbaum, "Coming out of the Closet: Librarian Advocacy to Advance LGBTQ+ Wikipedia Engagement," in LGBTQ+ Librarianship in the 21st Century: Emerging Directions of Advocacy and Community Engagement in Diverse Information Environments, ed. Mehra Bharat, Advances in Librarianship (Bingley, UK: Emerald Publishing Limited, 2019), 115-39; Matthew A. Vetter and Keon Pettiway, "Hacking Hetero/Normative Logics: Queer Feminist Media Praxis in Wikipedia," Technoculture: An Online Journal of Technology in Society 7 (2017), https://tcjournal.org/vol7/hacking-hetero-normative-logics.

24. Francesco Bellomi and Roberto Bonato, "Network Analysis for Wikipedia," in Inaugural Wikimania Conference (Frankfurt, Germany, 2005), 81, https://pdfs.semanticscholar.org/5bfa/b7aa1d3744b3a4da0d6c32f481f932390da2.pdf; Jonathan Morgan, Robert Mason, and Karine Nahon, "Negotiating Cultural Values in Social Media: A Case Study from Wikipedia" (paper presented at the Proceedings of the 45th Hawaii International Conference on System Sciences, Wailea, HI, 2012), 3490-99, https://doi.org/10.1109/hicss.2012.443; Roued-Cunliffe, "Forgotten History on Wikipedia," 67-76.

25. Ewa S. Callahan and Susan C. Herring, "Cultural Bias in Wikipedia Content on Famous Persons," Journal of the American Society for Information Science and Technology 62, no. 10 (2011): 1899-915, https://doi.org/10.1002/ asi.21577; Morgan, Mason, and Nahon, "Negotiating Cultural Values in Social Media," 3490-99.

26. Patti Bao et al., "Omnipedia: Bridging the Wikipedia Language Gap," in CHI Conference on Human Factors in Computing Systems (Austin, TX, 2012), https://collablab.northwestern.edu/pubs/CHI2012-BaoEtAl-Omnipedia. pdf; H. Wessler et al., "'Wikiganda': Detecting Bias in Multimodal Wikipedia Entries," in New Studies in Multimodality: Conceptual and Methodological Elaborations, eds. O. Seizov and J. Wildfeuer (London, UK: Bloomsbury Publishing, 2017), 175-200; Yiwei Zhou, Alexandra Cristea, and Zachary Roberts, “Is Wikipedia Really Neutral? A Sentiment Perspective Study of War-Related Wikipedia Articles since 1945" (paper presented at the Proceedings of the 29th Pacific Asia Conference on Language, Information and Computation, Shanghai, China, 2015), 160-68, https://www.aclweb.org/anthology/Y15-1019/; Paolo Massa and Frederico Scrinzi, "Manypedia: Comparing Language Points of View of Wikipedia Communities," First Monday 18, no. 1 (2013), https://firstmonday.org/ ojs/index.php/fm/article/view/3939/3382.

27. Paul Thomas, "Wikipedia and Participatory Culture: Why Fans Edit," Transformative Works and Cultures 22 (2016), https://doi.org/10.3983/twc.2016.0902; Johnny Au, “Single White Males: Systemic Bias in Wikipedia's 
Obsession," Wikipediocracy, http://wikipediocracy.com/2015/03/08/single-white-males-systemic-bias-in-wikipedias-obsessions/; Alexander Halavais and Derek Lackaff, "An Analysis of Topical Coverage of Wikipedia," Journal of Computer-Mediated Communication 13, no. 2 (2008): 429-40, https://doi.org/10.1111/j.1083-6101.2008.00403.x; O'Sullivan, Wikipedia, 81; Robert West, Ingmar Weber, and Carlos Castillo, "A Data-Driven Sketch of Wikipedia Editor" (paper presented at the Proceedings of the 21st International Conference on World Wide Web, Lyon, France, 2012), https://doi.org/10.1145/2187980.2188162.

28. Shane Greenstein and Feng Zhu, "Is Wikipedia Biased?" American Economic Review 102, no. 3 (2012): 343-48, https://www.aeaweb.org/conference/2012/retrieve.php?pdfid=297; Hube, "Bias in Wikipedia," 717-21.

29. Combahee River Collective in S.A. Mann and A.S. Patterson, Reading Feminist Theory: From Modernity to Postmodernity (Oxford, UK: Oxford University Press, 2016), 249. In using this specific definition, I aim to combine class analysis with a feminist focus on intersectionality, thereby tackling capitalism/class struggle, racism, and sexism all at once.

30. What Louis Althusser would later call "repressive state apparatuses." See: Louis Althusser, “Idéologie Et Appareils Idéologiques D'état (Notes Pour Une Recherche)," La Pensée 151 (1970), archived at http://classiques. uqac.ca/contemporains/althusser_louis/ideologie_et_AIE/ideologie_et_AIE_texte.html.

31. For example: schools, religious institutions, and government organizations; what Althusser would later call "ideological state apparatuses." See: Althusser, "Idéologie Et Appareils Idéologiques D'état (Notes Pour Une Recherche)."

32. Kate Crehan, Gramsci's Common Sense: Inequality and Its Narratives (Durham, NC: Duke University Press, 2016), $x$.

33. Antonio Gramsci, Selections from the Prison Notebooks, trans. Quintin Hoare and Geoffrey Nowell Smith (New York, NY: International Publishers, 1971).

34. Douglas Raber, "Hegemony, Historic Blocs, and Capitalism: Antonio Gramsci in Library and Information Science," in Critical Theory for Library and Information Science: Exploring the Social from across the Disciplines, eds. G.J. Leckie, L.M. Given, and J. Buschman (Santa Barbara, CA: Library Unlimited, 2010), 151.

35. Michael H. Harris, "State, Class, and Cultural Reproduction: Toward a Theory of Library Service in the United States," Advances in Librarianship 14 (1986): 211-52.

36. Connolly, cited in Harris, "State, Class, and Cultural Reproduction," 214.

37. Harris, "State, Class, and Cultural Reproduction," 215.

38. While many might argue that this category excludes university presses, it must be remembered that these presses are still producing and thus profiting from the reselling of products. (And some university presses are commercial juggernauts, such as the Oxford and Cambridge University Presses, which in 2019 made $£ 90.2$ million and $£ 22.4$ million in profit, respectively. See: Oxford UP Governance, "Annual Report," Oxford University Press, 2019, https://annualreport.oup.com/2019/finances/; Cambridge UP Governance, "Abstract of the Financial Statements," Cambridge University Press, 2019, https://www.cambridge.org/about-us/annual-report/finances.)

39. Wilhelm Peekhaus, "The Enclosure and Alienation of Academic Publishing: Lessons for the Professoriate," tripleC: Journal for a Global Sustainable Information Society 10, no. 2 (2012): 580-81, https://www.triple-c.at/index. php/tripleC/article/view/395; Iain Pirie, "The Political Economy of Academic Publishing," Historical Materialism 17 (2009): 36-37.

40. Peekhaus, "The Enclosure and Alienation of Academic Publishing," 584-85, 587.

41. Martin Paul Eve, OpenAccess and the Humanities: Contexts, Controversies and the Future (Cambridge, UK: Cambridge University Press, 2014), 34-36, https://doi.org/10.1017/CBO9781316161012.

42. Eve, OpenAccess and the Humanities, 580-81; Pirie, "Political Economy of Academic Publishing," 36-37.

43. Susan Merilainen et al., "Hegemonic Academic Practices: Experiences of Publishing from the Periphery," Organization 15, no. 4 (2008): 585-87.

44. Harris, "State, Class, and Cultural Reproduction," 216.

45. Stephen Bales, "Every Thing Determines Everything: Embracing the Flux of Academic Librarianship to Co-author Meaningful Change," Progressive Librarian 42 (2014): 149, http://www.progressivelibrariansguild.org/ PL/PL42/137.pdf.

46. Henry Giroux cited by João França, "Henry Giroux: 'Those arguing that education should be neutral are really arguing for a version of education in which nobody is accountable,"' CCCBLab (2019), http://lab.cccb.org/ en/henry-giroux-those-arguing-that-education-should-be-neutral-are-really-arguing-for-a-version-of-educationin-which-nobody-is-accountable/.

47. Alan Kirby, "The Death of Postmodernism and Beyond," Philosophy Now 58 (2006), https://philosophynow. org/issues/58/The_Death_of_Postmodernism_And_Beyond.

48. "Wikipedia: No Original Research," Wikimedia Foundation, last modified April 4, 2020, https://en.wikipedia. org/w/index.php?title=Wikipedia:No_original_research\&oldid=949186972; “Wikipedia: Reliable Sources,” Wiki- 
media Foundation, last modified May 3, 2020, https://en.wikipedia.org/w/index.php?title=Wikipedia:Reliable_ sources\&oldid=954688098; “Wikipedia: Verifiability," Wikimedia Foundation, last modified May 2, 2020, https:// en.wikipedia.org/w/index.php?title=Wikipedia:Verifiability\&oldid=954562837.

49. "Wikipedia: Reliable Sources."

50. "Wikipedia: No Original Research."

51. “Wikipedia: Neutral Point of View," Wikimedia Foundation, last modified May 4, 2020, https://en.wikipedia. org/w/index.php?title=Wikipedia:Neutral_point_of_view\&oldid=954806609.

52. "Wikipedia: Neutral Point of View."

53. Note that Wikipedia allows the limited use of primary sources, with the caveat that articles cannot be composed entirely of these sources. Primary sources must also come from someone that other editors have deemed reliable (such as a notable scholar or a celebrity).

54. Harris, "State, Class, and Cultural Reproduction," 243.

55. Bales, "Every Thing Determines Everything," 137-52; Harris, "State, Class, and Cultural Reproduction"; Douglas Raber, "Librarians as Organic Intellectuals: A Gramscian Approach to Blind Spots and Tunnel Vision," Library Quarterly 73, no. 1 (2003): 45.

56. For examples, see: Vetter and Pettiway, "Hacking Hetero/Normative Logics"; Peter Gellert and Maja van der Velden, "The Sum of all Human Knowledge? Wikipedia and Indigenous Knowledge," in At the Intersection of Indigenous and Traditional Knowledge and Technology Design, eds. N. Bidwell and H. Winschiers-Theophilus (Santa Rosa, CA: Informing Science Press, 2015), 125-26.

57. Thomas, "Wikipedia and Participatory Culture."

58. Wikipedia editors try to cull unsourced information on the site, but unsourced material is still to be found on millions of the site's articles. Other times, appropriately sourced articles turn out to be hoaxes. See, for instance: "Wikipedia: List of Hoaxes on Wikipedia," Wikimedia Foundation, May 6, 2020, https://en.wikipedia. org/w/index.php?title=Wikipedia:List_of_hoaxes_on_Wikipedia\&oldid=955228705.

59. For a simple example of Wikipedia's almost unconscious impact on the dissemination of information, see: Neil Thompson and Douglas Hanley, "Science Is Shaped by Wikipedia: Evidence from a Randomized Control Trial," (2018), https://conference.druid.dk/acc_papers/2862e909vshtezgl6d67z0609i5bk6.pdf.

60. For example: Vetter and Pettiway, "Hacking Hetero/Normative Logics"; Doyle, "Minding the Gaps," 55-69; Laurie M. Bridges and Meghan L. Dowell, "A Perspective on Wikipedia: Approaches for Educational Use," Journal of Academic Librarianship (2019): 1-3, https://doi.org/10.1016/j.acalib.2019.102090; Matthew A. Vetter et al., "Critical Digital Praxis in Wikipedia: The Art+Feminism Edit-a-Thon," Hybrid Pedagogy (2017), https://hybridpedagogy. org/wikipedia-art-feminism-edit-a-thon/.

61. "Wikipedia: WikiProject Countering Systemic Bias," Wikimedia Foundation, last modified April 18, 2020, https://en.wikipedia.org/w/index.php?title=Wikipedia:WikiProject_Countering_systemic_bias\&oldid=951704298 .62."Wikipedia: WikiProject Countering Systemic Bias."

63. To quote Robin Mansell, Imagining the Internet: Communication, Innovation, and Governance (Oxford, UK: Oxford University Press, 2012), 1-2.

64. For a similar discussion that problematizes the site's approach to sourcing, see: Vetter and Pettiway, "Hacking Hetero/Normative Logics," specifically the sections "Wikipedia's Politics of Citation" and "Consensus, Collaboration, and Dissensus: Disrupting Objectivism."

65. Gaby Weiner, "Scholarship, Disciplinary Hegemony and Power in Academic Publishing," in European Conference for Educational Research (University of Ljubljana, Slovenia, 1998).

66. Of note, this phrase is by no means new (having been introduced long ago in the field of textual criticism), but its use regarding Wikipedia is.

67. In particular: Paulo Freire, Pedagogy of the Oppressed, trans. M.B. Ramos, 30th anniversary ed. (New York, NY: Continuum, 2000); Education for Critical Consciousness (London, UK: Continuum, 2005); Paulo Freire and Ira Shor, A Pedagogy for Liberation: Dialogues on Transforming Education (London, UK: Macmillan Education, 1987).

68. In particular: Freire and Shor, A Pedagogy for Liberation; Ira Shor, "Education Is Politics: Paulo Freire's Critical Pedagogy," in Paulo Freire: A Critical Encounter, eds. Peter Leonard and Peter McLaren (New York, NY: Routledge, 1993).

69. In particular: Henry A. Giroux, Theory and Resistance in Education: A Pedagogy for the Opposition (Westport, CT: Bergin \& Garvey, 1983).

70. In particular: Sean Michael Morris and Jesse Stommel, An Urgency of Teachers: The Work of Critical Digital Pedagogy (Hybrid Pedagogy, 2018), https://urgencyofteachers.com/.

71. In particular: Vetter and Pettiway, "Hacking Hetero/Normative Logics."

72. As expressed in works like: Leckie, Given, and Buschman, Critical Theory for Library and Information Science; The Politics of Theory and the Practice of Critical Librarianship, eds. Karen P. Nicholson and Maura Seale (Sacramento, 
CA: Library Juice Press, 2018).

73. Cf. Morris and Stommel, An Urgency of Teachers, 2.

74. Vetter and Pettiway, "Hacking Hetero/Normative Logics."

75. For example, edit-a-thons; see: Vetter et al., "Critical Digital Praxis in Wikipedia."

76. Morris and Stommel, An Urgency of Teachers, 9.

77. Shor, "Education Is Politics," 32-33.

78. ACRL Board of Directors, Framework for Information Literacy for Higher Education, 12.

79. Shor, "Education Is Politics," 32.

80. Shor, "Education Is Politics," 33.

81. Freire and Shor, A Pedagogy for Liberation, 109.

82. Critical Mathematics Education: An Application of Paulo Freire's Epistemology, ed. Marilyn Frankenstein, Freire for the Classroom: A Sourcebook for Liberatory Teaching (Portsmouth, NH: Heinemann, 1987), 182.

83. Vetter and Pettiway, "Hacking Hetero/Normative Logics."

84. While much has been published about library-run institutional repositories, only a handful of articles specifically focus on how librarians and information professionals can use repositories to improve Wikipedia. See: Alastair Smith, "Wikipedia and Institutional Repositories: An Academic Symbiosis?" in Proceedings of ISSI 2011, eds. Ed Noyons, Patrick Ngulube, and Jacqueline Leta (SSI, Leiden University and University of Zululand, 2011), 801-10; Danielle Elder, R. Niccole Westbrook, and Michele Reilly, “Wikipedia Lover, Not a Hater: Harnessing Wikipedia to Increase the Discoverability of Library Resources," Journal of Web Librarianship 6, no. 1 (2012), https://doi.org/10.1080/19322909.2012.64180.

85. Vetter and Pettiway, "Hacking Hetero/Normative Logics."

86. "Wikipedia: Manual of Style," Wikimedia Foundation, last modified May 6, 2020, https://en.wikipedia. org/w/index.php?title=Wikipedia:Manual_of_Style\&oldid=955279064.

87. Morris and Stommel, An Urgency of Teachers, 183-87.

88. This is not an illicit practice and is, in fact, actively encouraged. See, for instance: “Wikipedia: WikiProject Encyclopaedia Britannica," Wikimedia Foundation, last modified May 4, 2020, https://en.wikipedia.org/w/index. php?title=Wikipedia:WikiProject_Encyclopaedia_Britannica\&oldid=954792094.

89. See: “Wikipedia: WikiProject Encyclopaedia Britannica" \& Use inline citation; “Template: Cite EB1911," Wikimedia Foundation, last modified August 14, 2019, https://en.wikipedia.org/w/index.php?title=Template:Cite_ EB1911\&oldid=909355174.

90. Morris and Stommel, An Urgency of Teachers, 179.

91. Pawley, "Hegemony's Handmaid?"

92. Bales, "Every Thing Determines Everything"; Harris, "State, Class, and Cultural Reproduction." 